Artigo: Poder, verdade e sexo: a padronização de formas de vida pela criação de categorias sexuais, à luz da teoria de Michel Foucault

\title{
PODER, VERDADE E SEXO: A PADRONIZAÇÃO DE FORMAS DE VIDA PELA CRIAÇÃO DE CATEGORIAS SEXUAIS, À LUZ DA TEORIA DE MICHEL FOUCAULT
}

\author{
POWER, TRUTH AND SEX: THE STANDARDIZATION OF LIFE FORMS BY THE \\ CREATION OF SEXUAL CATEGORIES, ACCORDING MICHEL FOUCAULT'S \\ THEORY
}

Thiago Augusto Galeão de Azevedo

\section{RESUMO:}

O presente artigo tem como objeto de análise o fenômeno da categorização sexual, à luz da teoria do filósofo Michel Foucault, principalmente a partir de sua obra História da sexualidade: a vontade de saber, visando-se averiguar em que medida o citado fenômeno, a categorização sexual, representa um instrumento do poder e da verdade incidentes sobre o sexo, um instrumento de padronização de formas de vida. Para tanto, optou-se, inicialmente, por uma reflexão acerca de leis, decretos e programas pátrios baseados em identidades sexuais, em categorias sexuais, apresentando-se, por sua vez, o sentido que o termo categoria sexual assume no presente ensaio; sustentando-se a sexualidade como uma construção, em forma de um dispositivo, responsável pela criação da ideia de sexo biológico, assim como pela produção das sexualidades desviantes, que precisaram ser nomeadas e catalogadas, para fins de controle. Seguidamente, fez-se, de forma breve, uma análise histórica, reconstrução histórica, no sentido foucaultiano, de desnaturalização do evidente; da sexualidade, averiguando-se o poder e a verdade incidentes sobre o sexo, tratando-se do chamado dispositivo de sexualidade. Em um terceiro momento, estudou-se a inversão teórica realizada por Michel Foucault, no que concerne à ideia de criação do sexo pelo citado dispositivo, dispositivo de sexualidade. Por fim, refletiu-se sobre a verdade e o poder incidentes sobre o sexo e o fenômeno da categorização sexual, identificação sexual, analisando-se a sua instrumentalização por aqueles, se as categorias sexuais cumprem um papel específico atribuído por aqueles.

PALAVRAS-CHAVE: Poder. Verdade. Sexo. Sexualidade. Categorias sexuais.

\section{ABSTRACT:}

This article has as his main object of analsys the phenomenon of sexual categorization, in consideration of philosopher Michel Foucault's theory, especially from his book History of sexuality: the will to knowledge, aiming to ascertain to what extent that phenomenon, sexual categorization, as an instrument of power and true incidents of sex, an instrument of standardization of forms of life. Therefore, we opted, initially, for a reflection on laws, decrees and patriotic programs based on sexual identities, on sexual categories, presenting, in turn, the sense that the term sexual category takes in this article; On that ground, Sexuality supporting himself as a construction in the form of a device, responsible for creating the idea of biological sex, as well as the production of deviant sexualities, which had to be named and cataloged, for controlling. Then, there was, briefly, a historical analysis, historical reconstruction, in Foucault's sense of sexuality, denaturalization of clear, reaching if power 
and truth of incidents on sex, in the case of so-called sexuality device. In a third time, moment, it was studied the theoretical investment made by Michel Foucault, regarding the idea of creating sex by that device, sexuality device. Finally, it was reflected on the truth and the power applied to the sex and the phenomenon of sexual categorizing, sexual identification, analyzing their instrumentalization by those, if the sexual categories play a specific role assigned by them.

KEYWORDS: Power. True. Sex. Sexuality. Sexual categories.

\section{INTRODUÇÃO}

O presente artigo tem como objeto de estudo o fenômeno da categorização sexual, da identificação dos indivíduos a partir de suas práticas sexuais, à luz da teoria de Michel Foucault, principalmente a partir de sua obra História da sexualidade: a vontade de saber no sentido de averiguar em que medida as categorias sexuais representam um instrumento do poder e da verdade incidentes sobre o sexo, de padronização de formas de vida.

Para tanto, inicialmente, tecer-se-á, sucintamente, considerações acerca de leis, programas e decretos pátrios pautados em categorias, em identidades sexuais. Esclarecendo-se o sentido que este termo assume no presente ensaio.

Em um segundo momento, realizar-se-á uma breve análise histórica, no sentido foucaultiano, da sexualidade, analisando-se os formatos de poder destacados por Foucault poder soberano, poder disciplinar, biopolítica das populações e biopoder assim como averiguar-se-á o poder e a verdade construída sobre o sexo, tratando-se, para tanto, do chamado dispositivo de sexualidade.

Seguidamente, analisar-se-á a inversão teórica realizada por Foucault, no que concerne à criação do sexo pelo dispositivo de sexualidade. O sexo, em seu caráter biológico, como um elemento criado, artificial.

Por fim, refletir-se-á sobre a verdade e o poder incidente sobre o sexo e a sua relação com o fenômeno da categorização sexual, propiciando-se uma análise acerca das identidades sexuais e a sua instrumentalização pela verdade e pelo poder incidente sobre o sexo.

\section{CATEGORIZAÇÃO SEXUAL}

Comumente chamado de "Bolsa Travesti”, a prefeitura de São Paulo lançou, em 29 de janeiro de 2015, o Programa "Transcidadania", que almeja oferecer a 100 indivíduos identificados como, destaca-se, travestis e transexuais uma bolsa de $\mathrm{R} \$ 840,00$ (oitocentos e 
Artigo: Poder, verdade e sexo: a padronização de formas de vida pela criação de categorias sexuais, à luz da teoria de Michel Foucault

quarenta reais), com o intuito de promover a sua educação e formação profissional. Para o recebimento do benefício, é necessária a matrícula em curso técnico do PRONATEC (Programa Nacional de Acesso ao Ensino Técnico e Emprego), a comprovação de frequência nas aulas e a realização da prova do ENEM (Exame Nacional de Ensino Médio).

O Estado de São Paulo, desde 2010, possui o chamado "Ambulatório de Saúde Integral para Travestis e Transexuais do Centro de Referência e Treinamento DST/AIDS-SP", ambulatório, destaca-se, especializado no atendimento de travestis e transexuais em tempo integral. Sua equipe profissional é formada por psicólogos, psiquiatras, endocrinologistas, urologistas e ginecologistas. Através de informações fornecidas pelo sítio eletrônico da prefeitura de São Paulo, os principais procedimentos oferecidos são "acolhimento; avaliação médica, endocrinológica, proctológica, fonoaudiológica e de Saúde Mental" (SÃO PAULO, 2015).

Em 2001, o governo do Estado de São Paulo editou a lei n ${ }^{\circ} 10.948$, que dispõe sobre penalidades a serem aplicadas a atos discriminatórios em razão da orientação sexual. $\mathrm{O}$ art. $1^{\circ}$ da referida lei expõe que serão punidas todas as manifestações atentatórias ou discriminatórias praticadas contra cidadãos, destaca-se, homossexuais, transexuais ou transgêneros.

O governo do Estado do Rio Grande do Sul, através do Decreto ${ }^{\circ}$ 48.118, de junho de 2011, determinou que nos procedimentos e atos dos órgãos da administração pública direta e indireta de atendimento, destaca-se, a travestis e transexuais seja assegurado o direito à escolha de seu nome social, independentemente de registro civil.

Percebe-se, através da exposição das referidas leis, programas e decretos; a presença de um elemento em comum: a afirmação de categorias sexuais, identidades sexuais; a definição sexual de seus beneficiários, sejam eles travestis, transexuais, homossexuais, bissexuais, transgêneros ou lésbicas. Sejam eles quem forem, mas que sejam identificados, categorizados sexualmente.

Trata-se da afirmação de direitos a minorias, ditas minorias sexuais. Direitos estes que são afirmados a partir da especificação, da definição clara e expressa dos seus titulares. Uma identificação, classificação sexual dos grupos a serem beneficiados por tais direitos.

Lésbicas, gays, bissexuais, transexuais, travestis, transgêneros, intersexuais, pansexuais, assexuais. Citando Regina Fachinni (2002), trata-se de uma "sopa de letrinhas", que identifica os indivíduos a partir de suas práticas ditas sexuais.

Nesse contexto, analisar-se-á, a partir do presente artigo, em que medida o citado fenômeno da categorização sexual representa um instrumento de poder incidente sobre o sexo, 
à luz dos ensinamentos de Michel Foucault. Para tanto, estudar-se-ão os elementos sexo, sexualidade e poder, em Michel Foucault, a partir, primordialmente, de sua obra História da sexualidade: a vontade de saber.

\section{BREVE ANÁLISE HISTÓRICA DA SEXUALIDADE: DISPOSITIVO DE SEXUALIDADE}

Entende-se como fundamental para a compreensão da análise histórica da sexualidade, assim como do sujeito sexual, a exposição, de forma sucinta, dos três formatos de poder próprios à teoria de Michel Foucault. Trata-se do poder soberano, poder disciplinar e biopolítica das populações, estes dois últimos constituintes do chamado biopoder. Propiciando-se, dessa forma, o substrato teórico necessário para a compreensão das questões a serem levantadas no presente texto.

Inicia-se com o poder soberano, que teve como um de seus privilégios o direito de vida e morte, derivado do patria potestas, o qual ensejava a disposição da vida dos filhos e dos escravos pertencentes ao pai de família romano. Uma sociedade marcada pela "extorsão de produtos, de bens, de serviços, de trabalho e de sangue imposta aos súditos" (FOUCAULT, 2014a, p. 146). Nesta, o poder assume um caráter de direito de apreensão, apreensão das coisas, do tempo, dos corpos, da vida. Trata-se de uma apoderação da vida com fins de supressão.

Entretanto, foi a partir da época clássica que houve uma transformação no poder soberano. O confisco perdeu a sua centralidade, cedendo espaço aos elementos com função de “incitação, de reforço, de controle, de vigilância, de majoração e de organização das forças que lhe são submetidas" (FOUCAULT, 2014a, p. 146). Trata-se de um poder produtor de forças, com o objetivo de fazê-las crescer e ordenar, mais do que limitá-las, brecá-las ou destruí-las.

Um mecanismo de poder incidente sobre a vida, que, de acordo com Foucault (2014a), desenvolveu-se a partir do século XVII, através de duas formas de poder. A primeira relacionada às "disciplinas do corpo", o corpo como uma máquina, que deve ser adestrada, ter suas aptidões expandidas, suas forças extorquidas. Visava-se a majoração da utilidade e docilidade do corpo, através de um sistema de controle eficaz e econômico, "tudo isso assegurado por procedimentos de poder que caracterizam as disciplinas: anátomo-política do corpo humano." (FOUCAULT, 2014a, p. 150). 
Artigo: Poder, verdade e sexo: a padronização de formas de vida pela criação de categorias sexuais, à luz da teoria de Michel Foucault

Quanto à segunda forma de poder exercida sobre a vida, Foucault (2014a) comenta que foi formada aproximadamente na metade do século XVIII, estando relacionada a "regulações da população". Tem-se como foco não mais o indivíduo, mas o "corpo-espécie", a população, a sua espécie. O corpo é atravessado por intervenções e controles regulares, exercidos com base nos chamados "processos biológicos", como reprodução, nascimento, mortalidade, longevidade, nível de saúde, expectativa de vida e as suas variantes. Trata-se de uma "mecânica do ser vivo".

Considerando as citadas duas formas de poder, identifica-se um conjunto de técnicas fundadas na sujeição dos corpos e no controle das populações, chamado de "biopoder", ou conforme já mencionado, a era do biopoder. Foucault (2014a) associa o capitalismo ao biopoder; o capitalismo, assim, associado à introdução da vida no domínio do poder e do saber, das técnicas políticas. A partir de certo domínio sobre a vida, através do desenvolvimento de conhecimentos sobre ela mesma, e a partir da fixação de medidas que visavam a vida e a sobrevivência, as iminências da morte eram afastadas.

O poder é exercido sobre a vida, o que lhe dá o acesso ao corpo. Entretanto, tais tecnologias políticas vão incidir, além de sobre o corpo e saúde, sobre a alimentação do indivíduo, habitação, condições de vida; sobre toda a sua existência.

No que concerne à sexualidade, o regime de poder, saber e prazer não estariam limitados a uma repressão, mas marcado por um falar sobre a sexualidade, por instituições que incitam tal ato, qual seja: "a colocação do sexo em discurso", com o objetivo de revelar a "vontade de saber" subjacente às produções discursivas. O mecanismo de poder referente à sexualidade não foi exercido através de uma lógica repressiva apenas, mas principalmente através de uma incitação, da disseminação das sexualidades polimorfas.

Precisava-se falar sobre o sexo, contar todos os seus detalhes, a fim de que se fixassem regras para o exame dos próprios atos daqueles que confessam. Tudo o que fosse considerado carnal, sexual, deveria ser confessado e ser objeto de um aconselhamento espiritual, medindose, entretanto, a nudez das palavras. Nas palavras de Foucault (2014b, p. 309):

Tudo não é verdade. Mas em todo ponto, e a todo momento, há uma verdade a dizer e a ver, uma verdade que dormita, talvez, mas que não se espera senão nosso olhar aparecer, nossa mão para desvelar-se; cabe a nós encontrar a boa perspectiva, o ângulo conveniente, os instrumentos necessários, pois, de qualquer forma, ela está ali e está ali por toda parte. 
Passa-se a interrogar a sexualidade das crianças, dos criminosos, dos loucos e o prazer daqueles que não amam o "sexo oposto". Surgindo, desta forma, um mundo chamado, por Foucault (2014a), de "mundo da perversão", habitado por indivíduos denominados de "gentalha diferente". Indivíduos que foram perseguidos durante o período do séc. XVIII ao século XX pelas leis vigentes.

Entre tais perversos está aquele que não se enquadra na lógica heterossexual, que não sente prazer no "sexo oposto"; ele é considerado aberrante, habitante do mundo da perversão. Surgem, desta forma, as sexualidades periféricas, dotadas de um atributo de anormalidade, à luz da lógica dominante heterossexual. Tais indivíduos são considerados "vizinhos" dos delinquentes e semelhantes aos loucos.

Diante do teor patológico das consideradas práticas sexuais incompletas, a medicina tratou de classificar também todas as formas de prazeres que seguiam a referida lógica, marcada pela ausência. Assim, identificaram-se as sexualidades que não seguiam os padrões dominantes, que não seguiam a lógica heterossexista. Estas precisavam ser identificadas, expostas à fala. Precisava-se conhecer tudo sobre elas. Apenas conhecendo-as por inteiro que o controle poderia ser exercido de forma completa e eficaz. Classificar e gerir.

Há uma perseguição às sexualidades periféricas, com o intuito de controlá-las, inserindo-as em uma lógica analítica e permanente, no sentido de encravar tais sexualidades nos corpos dos indivíduos, em suas condutas, tornando-os objetos de classificação. Em relação a tais sexualidades periféricas, Márcio Alves da Fonseca (2003, p. 85) comenta:

\footnotetext{
Há, assim, um mecanismo de multiplicação discursiva em função do aparecimento de inúmeras heterogeneidades sexuais, tratadas doravante de maneira diversa das interdições, mas de forma a contar com presenças constantes e atentas, submetidas a exames e observações.

O conjunto das sexualidades múltiplas, surgidas com o discurso médico sobre o sexo, deve ser entendido como correlato de procedimentos de poder, que agem sobre os corpos e seus prazeres, de modo a incitá-los e examiná-los e nunca a prescrever interdições.
}

Não se trata, portanto, de uma exclusão dessas "sexualidades aberrantes", e sim de uma especificação, padronização delas. Nas palavras de Foucault (2014a, p. 49): "trata-se, através de sua disseminação, de semeá-las no real e de incorporá-las ao indivíduo.”.

O poder incidente sobre tais sexualidades periféricas é impulsionado pelo seu próprio funcionamento. A sexualidade é provocada quando se torna objeto da medicina, das 
Artigo: Poder, verdade e sexo: a padronização de formas de vida pela criação de categorias sexuais, à luz da teoria de Michel Foucault

inquirições médicas, no sentido de que com a incitação do falar da sexualidade, o prazer é incitado, conjuntamente. O corpo sexual é provocado.

Trata-se de um mecanismo de incitação do prazer e do poder. Um poder dotado de um prazer mediante o seu caráter questionador, fiscalizador, que investiga, escuta, instiga e revela. Um poder que desperta o prazer naquele que é instigado. Assim, por meio da instigação do prazer, este é revelado. Sucessivamente, fixado. Anotado. Controlado. Uma lógica de captação e sedução.

O sexo é saturado, incitado em exaustão pelos chamados "dispositivos de saturação sexual" (FOUCAULT, 2014a), característicos do século XIX. Através da exaustão do sexo, as diversas formas de sexualidades são expostas e, sucessivamente, penetradas pelo poder, redutor das sexualidades singulares, uma vez que criou sexualidades sob a medida de molduras pré-fixadas, em classificações pautadas na idade, em determinados gostos, em tipos de relacionamentos e no lugar definido. Sexualidades múltiplas perpetradas pelo poder, pela incitação e pela fixação. Nas palavras de Foucault (2014a, p. 53):

[...] as sexualidades múltiplas - as que aparecem com as idades (sexualidade do lactente ou da criança), as que fixam em gostos ou práticas (sexualidade do invertido, do gerontófilo, do fetichista...), as que investem difusamente no relacionamento (sexualidade do lar, da escola, da prisão) - constituem o correlato de procedimentos precisos de poder.

A multiplicidade sexual foi, através dos dispositivos de poder, consolidada no corpo do próprio homem. "Através de múltiplos dispositivos de poder, foram solicitados, instalados, isolados, intensificados, incorporados." (FOUCAULT, 2014a, p. 53), ou seja, as sexualidades periféricas, consideradas perversões, foram solicitadas e fixadas no indivíduo, incluindo-as no seu corpo, de uma forma que os identifiquem. Trata-se de um sujeito sexual.

Deve-se abandonar, portanto, a ideia de que as sociedades modernas iniciaram um período de repressão do sexo. Pelo contrário, percebe-se uma intensificação de discursos sobre ele, sobre o dizer. Trata-se de um poder que possui como elemento central o sexo. Um poder desvelador do prazer e criador de sexualidades periféricas. Para Foucault (2014a), um poder diferente da lei. Apesar de pontualmente estar baseado em procedimentos de interdição, assegura a disseminação de prazeres e a multiplicação de sexualidades, através de mecanismos que se conectam, que se cruzam.

A partir do séc. XVIII, Foucault (2014a) sustenta que se pôde identificar conjuntos estratégicos sobre o sexo, desenvolvedores de dispositivos de poder e de saber. Uma nova 
tecnologia de poder surgia, na qual o sexo possuía um papel central apartada das questões religiosas, da Igreja, da instituição eclesiástica, fundamentada na medicina, na pedagogia e na economia, que fizeram do sexo uma questão, um interesse, um negócio de Estado. O corpo social, quase todos os indivíduos que o compunham, foi obrigado a se colocar em vigilância. O efeito de tais estratégias de poder foi a produção da sexualidade, enquanto dispositivo. Nas palavras de Foucault (2014a, p. 115):

\begin{abstract}
A sexualidade é o nome que se pode dar a um dispositivo histórico: não à realidade subterrânea que se apreende com dificuldade, mas à grande rede da superfície em que a estimulação dos corpos, a intensificação dos prazeres, a incitação ao discurso, a formação dos conhecimentos, o reforço dos controles e das resistências encadeiam-se uns aos outros, segundo algumas grandes estratégias de saber e de poder.
\end{abstract}

Trata-se de um novo dispositivo, típico das sociedades modernas, o dispositivo da sexualidade. Estruturado em técnicas dotadas de mobilidade, polimorfas de poder, está preocupado em estender as formas de controle e os domínios, não tendo como objetivo reproduzir, mas "proliferar, inovar, anexar, inventar, penetrar nos corpos de maneira cada vez mais detalhada e controlar as populações de modo cada vez mais global." (FOUCAULT, 2014, p. 37).

Uma tecnologia de poder herdeira do cristianismo. Trata-se de uma continuidade, mas marcada por uma transformação paradigmática. Ao invés da questão da morte e do castigo perpétuo, da vida e da doença, o foco passa a ser o caráter médico, destaca-se, a imposição de uma normalidade. Nas palavras de Foucault, "a carne é transferida para o organismo" (2014a, p. 127). Uma transformação que ocorreu na transição do séc. XVIII para o séc. XIX, ensejando várias modificações derivadas.

Em todos os eixos que o dispositivo de sexualidade se desenvolveu se elaborou a ideia de que existe um além, algo além dos “corpos, órgãos, localizações somáticas, funções, sistemas anátomo-fisiológicos, sensações, prazeres; algo diferente e a mais, algo que possui suas propriedades intrínsecas e suas leis próprias", trata-se do sexo.

O dispositivo de sexualidade como o responsável pela produção da ideia de sexo, em uma concepção biológica, intimamente, relacionada à criação de sexualidades múltiplas, desviantes é o que será exposto e analisado, detidamente, na seção a seguir, destacando-se o poder e a verdade incidentes sobre o sexo. 
Artigo: Poder, verdade e sexo: a padronização de formas de vida pela criação de categorias sexuais, à luz da teoria de Michel Foucault

\section{A CRIAÇÃO DO SEXO}

Para Foucault (2014a), o dispositivo de sexualidade foi o responsável pela criação e instauração da ideia de sexo. A noção de sexo produziu uma "reversão essencial", que permitiu travestir a relação positiva, entre poder e sexualidade, de uma relação negativa, no sentido de que o poder sujeitaria a sexualidade, ou seja, o poder seria o responsável por uma repressão da sexualidade.

A partir de uma natureza biológica, “a ideia 'do sexo' permite esquivar o que constitui o 'poder' do poder" (2014a, p. 169). Em outras palavras, considerando o sexo como um elemento natural este não aparece como construção, como objeto atravessado pelo dispositivo da sexualidade. O poder aparece apenas em sua versão de interdição, de lei.

O sexo, como um elemento imaginário produzido pelo dispositivo de sexualidade, passa a ser "[...] o elemento mais especulativo, mais ideal e igualmente mais interior, num dispositivo de sexualidade que o poder organiza em suas captações dos corpos, de sua materialidade, de suas forças, suas energias, suas sensações, seus prazeres." (Foucault, 2014a, p. 169).

A partir da criação do citado elemento imaginário, o sexo, o dispositivo de sexualidade suscitou um dos seus princípios internos de funcionamento, dito essencial, o desejo do sexo. Tal desejo inclui o ter, ter acesso a ele, descobri-lo, desbravá-lo, desenterrá-lo, suscitá-lo em discurso, "formulá-lo em verdade". Sobre o desejo do sexo e seu caráter criado, destaca-se as palavras de Foucault (2014a, p. 170-171):

\footnotetext{
É essa desirabilidade do sexo que fixa cada um de nós à injunção de conhecê-lo, de descobrir sua lei e seu poder; é essa desirabilidade que nos faz acreditar que afirmamos contra todo poder os direitos de nosso sexo quando, de fato, ela nos vincula ao dispositivo de sexualidade que fez surgir, do fundo de nós mesmos, como uma miragem onde acreditamos reconhecer-nos, o brilho negro do sexo.
}

Em relação à sexualidade e ao sexo, Foucault (2014a) comenta que o primeiro é uma "figura histórica muito real", intimamente relacionada ao dispositivo de sexualidade, responsável por suscitar o sexo, como um elemento necessário para o seu funcionamento, um elemento especulativo.

Foucault (2014a), atinente à sexualidade e ao sexo, realiza uma inversão na lógica de que a primeira deriva do segundo. Para ele, é o dispositivo de sexualidade que cria e instaura 
o sexo. Em entrevista publicada na obra Microfísica do poder, as palavras de Foucault sobre tal inversão (2011, p. 258-259):

\begin{abstract}
A.G.: Como você define o que você chama de sexo em relação a este dispositivo de sexualidade? Trata-se de um objeto imaginário, um fenômeno, uma ilusão?

M.F,: Vou dizer a você como as coisas aconteceram. Houve muitas redações sucessivas. No começo, o sexo era um dado prévio e a sexualidade aparecia como uma espécie de formação ao mesmo tempo discursiva e institucional, articulando-se com o sexo, recobrindo-o e mesmo o ocultando. Esta era a primeira linha de análise. Mostrei depois o manuscrito a algumas pessoas e senti que não era satisfatório. Resolvi então inverter tudo. Era um jogo, pois não estava muito seguro... Mas dizia a mim mesmo: no fundo, será que o sexo, que parece ser uma instância dotada de leis, coações, a partir de que se definem tanto o sexo masculino quanto o feminino, não seria ao contrário algo que poderia ter sido produzido pelo dispositivo de sexualidade? O discurso de sexualidade não se aplicou inicialmente ao sexo, mas ao corpo, aos órgãos sexuais, aos prazeres, à relações de aliança, às relações interindividuais, etc...

J.-A.M.: Um conjunto heterogêneo...

M.F.: Sim, um conjunto heterogêneo que estava recoberto pelo dispositivo de sexualidade que produziu, em determinado momento, como elemento essencial de seu próprio discurso e talvez de seu próprio funcionamento, a ideia de sexo.
\end{abstract}

Um sexo que não é contemporâneo da instauração do dispositivo de sexualidade. Para Foucault (2011) existe uma sexualidade após o século XVIII e um sexo após o século XIX. Anteriormente, a carne. Assim, a sexualidade não seria derivada do corpo, pelo contrário, ela toma os corpos como seu objeto, sobre o qual incide o seu poder. Investe os corpos com o sexo. O sexo como elemento criado, fruto de um mecanismo de poder, fruto de uma correlação de forças, fruto do dispositivo de sexualidade (BUTLER, 2008).

Judith Butler, filósofa contemporânea, considerada como uma das expoentes da chamada Teoria Queer (apresentação esta que seria, na verdade, contraditória com o que ela sustenta, por ser limitativa e definidora) compartilha da concepção foucaultiana sustentadora do sexo como um elemento criado. Para a filósofa (2014) o sexo, assim como o gênero, é produzido culturalmente, não podendo ser considerado uma "substância permanente", tendo em vista que é efeito de uma coerência produzida pela cultura heterossexual, com o intuito de legitimar e manter o que a crítica feminista Adrienne Rich chamou de "heterossexualidade compulsória" (SALIH, 2013). 
Artigo: Poder, verdade e sexo: a padronização de formas de vida pela criação de categorias sexuais, à luz da teoria de Michel Foucault

\section{CATEgORIAS SEXUAis E A CRIAÇÃO DE UM SUJEITO SEXUAL: PADRONIZAÇÃO DE FORMAS DE VIDA}

O dispositivo de sexualidade, como o elemento criador de um sujeito sexual, refere-se a um sujeito identificado a partir de sua sexualidade. Quem você é? Não. Passa-se a perguntar “Que ser sexual é você?". Nas palavras de Foucault (2014b, p. 338):

É exatamente assim. Na cultura grega, que conhecia os aphrodisia, era simplesmente impensável que alguém fosse essencialmente homossexual em sua identidade. Havia pessoas que praticavam aphrodisia convenientemente, segundo os costumes, e outras que não os praticavam bem, mas o pensamento de identificar alguém segundo sua sexualidade não poderia vir-lhes à ideia. Foi somente quando o dispositivo da sexualidade estava efetivamente estabelecido, quer dizer, quando um conjunto de práticas, instituições e conhecimentos havia feito da sexualidade um domínio coerente e uma dimensão absolutamente fundamental do indivíduo, foi nesse momento preciso que a questão 'Que ser sexual é você?' tornou-se inevitável.

Assim, dizer sim ao sexo não possui um caráter subversivo à estrutura de poder, pelo contrário, trata-se de um ato de aderência ao dispositivo geral de sexualidade. A subversão à referida estrutura de poder é incompatível com a noção de sexo. Nas palavras de Foucault, "contra o dispositivo de sexualidade, o ponto de apoio de contra-ataque não deve ser o sexodesejo, mas os corpos e os prazeres" (2014a, p. 171). O filósofo comenta a incitação do discurso sobre o sexo e os mecanismos de poder da sexualidade (2014a, p. 172-174):

E lá, onde hoje vemos a história de uma censura dificilmente suprimida, reconhecerse-á, ao contrário, a lenta ascensão, através dos séculos, de um dispositivo complexo para nos fazer falar do sexo, para lhe dedicarmos nossa atenção e preocupação, para nos fazer acreditar na soberania de sua lei quando, de fato, somos atingidos pelos mecanismos de poder da sexualidade.

[...] há vários séculos, fizeram-nos amar o sexo, tornaram desejável para nós conhecê-lo e precioso tudo o que se diz a seu respeito; pelos quais, também, incitaram-nos a desenvolver todas as nossas habilidades para surpreendê-lo e nos vincularam ao dever de extrair dele a verdade; pelos quais nos culpabilizaram por têlo desconhecido por tanto tempo. São esses ardis que mereceriam espanto hoje em dia. E devemos pensar que um dia, talvez, numa outra economia dos corpos e dos prazeres, já não se compreenderá muito bem de que maneira os ardis da sexualidade e do poder que sustêm seu dispositivo conseguiram submeter-nos a essa austera monarquia do sexo, a ponto de votar-nos à tarefa infinita de forçar seu segredo e de extorquir a essa sombra as confissões mais verdadeiras.

Ironia desse dispositivo: é preciso acreditarmos que nisso está nossa 'liberação'.

Destaca-se a incitação ao discurso sobre o sexo, a interrogação do mesmo, a fim de se procurar uma verdade em um elemento criado. Finge-se resgatar a sexualidade de uma obscuridade, através dos discursos, hábitos, instituições, regulamentos e saberes da sociedade 
ocidental. Desobscurecer uma sexualidade que tudo "trazia à plena luz e refletia com estrépito.” (2014a, p. 172).

O sexo como um elemento natural, um elemento biológico, uma condição biológica do indivíduo; a sexualidade sendo apenas uma consequência dele. O sexo como um elemento inserido em uma lógica biológica coerente, que prega que o indivíduo já nasce com um sexo pré-determinado (BUTLER, 2008).

Sobre o sexo como um elemento pré-discursivo, natural, Judith Butler comenta (2014, p.25) que "na conjuntura atual, já está claro que colocar a dualidade do sexo num domínio pré-discursivo é uma das maneiras pelas quais a estabilidade interna e a estrutura binária do sexo são eficazmente asseguradas".

Trata-se, portanto, de uma lógica heterossexual. O sexo é construído em um discurso que prega a sua naturalidade e a sua relação consequencial com a sexualidade. Uma lógica heterossexual, marcada por dois produtos: macho e fêmea. Estes são os coerentes, tudo o que estiver fora disso é considerado anormal, incompleto, incoerente; devendo ser objeto de controle.

Os perversos sexuais se tornaram objeto da medicina, que criou uma patologia orgânica intrínseca às práticas sexuais que não se amoldavam à lógica heterossexual. Estas eram consideradas incompletas, dotadas de uma anormalidade.

Como efeito, a medicina catalogou todas as formas de prazer que destoavam das que eram praticadas através da penetração falocêntrica. $\mathrm{O}$ conhecimento e o mapeamento destas eram necessários para que o controle pudesse ser exercido de forma efetiva e total. Classificaram-se todas as sexualidades destoantes da lógica dominante heterossexual. Uma medicina classificatória, conforme Fonseca comenta (2002, p. 51):

\footnotetext{
Antes do final do século XVIII a medicina pode ser considerada uma medicina classificatória. Para este conjunto de saberes a doença consistia numa entidade ideal e devia ocupar um lugar num quadro classificatório de suas espécies. O modelo desta medicina é aquele da história natural, modelo botânico e taxonômico. Assim como os vegetais podiam ser classificados em gêneros e espécies, as doenças eram percebidas em seus sintomas, sua externalização, e a medicina teria o papel de distribuí-las num quadro.
}

Para tanto, aplicaram-se questionários médicos. Precisava-se ter o conhecimento de tudo, o maior número de informações. Um poder exercido através de investigação, de escutas, de instigação e revelação. O dizer sexual era necessário, era incitado e anotado. Um poder que desvela um prazer no investigado. O prazer sexual é provocado, incitado, manifestado e, 
Artigo: Poder, verdade e sexo: a padronização de formas de vida pela criação de categorias sexuais, à luz da teoria de Michel Foucault

posteriormente, anotado. Trata-se do duplo efeito do poder, este incita o prazer, a sua manifestação, para que através dele possa exercer um controle. O prazer sexual é seduzido a se manifestar, para ser capturado, posteriormente.

O objetivo não era condenar as sexualidades periféricas, e sim geri-las, gerenciá-las. O dizer sexual assume o papel de fornecedor do material interpretativo para o controle. $\mathrm{O}$ controle das sexualidades, através do mapeamento das sexualidades ilegítimas; as diversas formas de sexualidade são expostas, detalhadas e atravessadas pelo poder.

Para a realização do referido controle eram necessários dados para o conhecimento do objeto, material este fornecido pelo dizer sexual, pela incitação da fala sobre o sexo. Entretanto, o conhecimento sobre o objeto não bastava, para este ser controlado era necessário especificar, mapear, catalogar as múltiplas sexualidades.

Assim, destaca-se que as sexualidades múltiplas foram construídas a partir de uma estrutura de poder e verdade, qual seja: o dispositivo de sexualidade, responsável pela criação da ideia de sexo, sustentando-o como um elemento natural, biológico e coerente, conforme analisado anteriormente. Trata-se da inversão realizada por Foucault, a partir da qual se infere que o sexo é um elemento criado, produzido, atravessado pelo poder.

Precisava-se controlar a anormalidade, a patologia. Era necessário identificar aqueles que não se amoldavam à lógica heterossexual. Estes precisavam ser especificados, catalogados, para serem controlados. Dessa forma, criaram-se as sexualidades periféricas, múltiplas. Estas são produtos do mecanismo de poder incidente sobre a vida.

A categorização sexual, a partir da criação e especificação das sexualidades periféricas, das perversões; como um instrumento de controle, de redução de formas de vidas sexuais. O produto factual do dizer sexual do indivíduo, quando semelhante ao de outro, é emoldurado em uma sexualidade. O indivíduo e sua vida sexual estão petrificados em uma definição externa, em uma definição do incomensurável.

Há, portanto, uma redução de singularidades. A vida do indivíduo é encaixada, emoldurada, moldada em um padrão de sexualidade, ou melhor, na própria sexualidade. Trata-se de um nítido apagamento de formas de vidas. O indivíduo deve se encaixar em uma gaveta pré-fabricada.

Como já se disse, o dispositivo de sexualidade toma os corpos como seu objeto e instrumento de poder. Investe os corpos com a ideia de sexo, como elemento biológico, imutável. Assim, produz corpos sob a égide da lógica que prega a coerência sexual, a integridade heterossexual. Produz corpos sexualizados, identificados através de sua 
sexualidade. Nas palavras de Butler (2008, p. 98): “[...] a sexualidade toma corpos como seu instrumento e objeto, o lugar em que ela consolida, enreda e estende seu poder.".

As sexualidades múltiplas, perversões, são incitadas, criadas e fixadas nos indivíduos, em seus corpos. Há uma fixação da categoria sexual criada no corpo do indivíduo. A partir desta, o indivíduo passa a ser identificado através de sua sexualidade. O indivíduo passa a ter uma identidade sexual, criada para medir a sua vida. Não pode ser livre, não! Precisa se amoldar, ser categorizado, especificado, para que o seu perigo possa ser mantido em controle, para que o poder próprio à sexualidade o controle de forma mais fácil, útil e eficaz.

Assim como o sexo, criam-se as sexualidades periféricas. Trata-se de uma das características do mecanismo de poder vigente, que atua através da criação do objeto que pretende regular. Produzem-se as sexualidades múltiplas, as perversões, com fins de controle, de regulação, gerenciamento.

Para Butler, entretanto, a criação e o controle não se trata de momentos diferentes. Não se cria o sexo, não se criam as sexualidades periféricas para que estas depois sejam reguladas. A criação e a regulação ocorrem ao mesmo tempo, uma vez que para a filósofa a regulação é sempre produtiva. Em suas palavras (2008, p. 96):

\footnotetext{
Não é como se o regime regulador primeiro controlasse seu objeto e então o produzisse ou primeiro o produzisse para então controlá-lo; não há um intervalo temporal entre produção e a regulação do sexo; elas ocorrem ao mesmo tempo, pois a regulação é sempre geradora, produzindo o objeto que ela alega apenas descobrir ou encontrar no campo social em que opera.
}

Destaca-se, portanto, que o dispositivo de sexualidade para controlar as sexualidades múltiplas, as sexualidades que não se amoldam à lógica heterossexual, criou-as, especificouas e as nomeou. Foi necessário produzir sexualidades periféricas, pautadas em um padrão também produzido, qual seja: o sexo em aspectos biológicos, heterossexuais.

Identifica-se, assim, uma dupla criação atinente às categorias sexuais. Primeiro, a criação do sexo pelo dispositivo de sexualidade. O sexo na concepção biológica, imutável, como pré-condição para a sexualidade. Um sexo dotado de naturalidade, o qual origina a heterossexualidade, também considerada natural. Segundo, a criação das sexualidades periféricas pautadas na primeira criação. Tais sexualidades foram criadas tendo como base a concepção biológica do sexo, a concepção que prega como normal o casal dito heterossexual, a relação marcada pela penetração falocêntrica. Aquilo que fugir a essa lógica deve ser identificado, controlado, regulado. 
Artigo: Poder, verdade e sexo: a padronização de formas de vida pela criação de categorias sexuais, à luz da teoria de Michel Foucault

Infere-se, portanto, que as sexualidades periféricas possuem como fundamento o sexo, em sua concepção biológica construída. Este é considerado o paradigma para a identificação e classificação de formas de vidas sexuais dissidentes com a lógica dominante.

As sexualidades múltiplas, perversões, são incitadas, criadas e fixadas nos indivíduos, em seus corpos. Há uma fixação da categoria sexual criada no corpo do indivíduo. O indivíduo passa a ser identificado através de sua sexualidade. Conforme citado anteriormente, para se conhecer o indivíduo, pergunta-se: que ser sexual é você?

\section{CONSIDERAÇÕES FINAIS}

Em linhas de conclusão, pôde-se identificar uma estrutura de poder e verdade construída sobre o sexo. Trata-se de um dispositivo de poder, o dispositivo de sexualidade, responsável pela criação da ideia de sexo, este como um elemento dotado de uma naturalidade. Uma verdade construída sobre o sexo e a sexualidade, aquele como um fator biológico, imutável e intrínseco ao individuo, em relação ao qual a sexualidade derivaria. Um dispositivo de poder que encapuza a construção do sexo e da sexualidade, naturalizando-os a partir da concepção biológica, sustentada como a dotada de normalidade.

Defende-se que se trata de um poder que se manifesta através de dois dos formatos de poder destacados por Foucault, poder disciplinar, incidente sobre o corpo, e biopolítica das populações, constituintes do chamado biopoder, um poder positivo, empreendedor, onipresente.

É com base na verdade construída em relação ao sexo, o sexo biológico, que a concepção naturalizada de sexualidade é formada. Esta como uma derivação lógica e coerente do sexo "natural" de cada indivíduo. Um sexo e uma sexualidade que define o indivíduo, que passa a ser um sujeito sexual.

A partir da lógica natural e binária do sexo, produz-se a ideia de sexualidades normais e desviantes, estas como as que não seguem o padrão binário "natural", o padrão biológico "heterossexual". Por isso merecem ser criadas, especificadas e incorporadas nos indivíduos, identificando-os, com fins de gerenciamento e controle. Trata-se de uma lógica de poder e verdade construída sobre o sexo, diretamente relacionada com a construção da ideia naturalizada de sexualidade e do sujeito sexual. 
Assim, o fenômeno da categorização sexual representaria um instrumento de controle do Poder e Verdade construídos sobre o sexo, propiciando uma padronização de formas de vida, no sentido de que os indivíduos, ao invés de exercerem um devir, um processo ininterrupto de experiências, precisariam estar presos à ideia do ser.

Ser um sujeito sexual, um indivíduo identificado pela sua prática sexual, deve ser um indivíduo estranho, anormal, em relação ao padrão de normalidade sexual construído a partir da concepção biológica e coerente. Categorizem-se! Saiam do armário! Em outras palavras: reconheçam-se como anormais! Reconheçam-se como alienígenas sexuais!

\section{REFERÊNCIAS}

BUTLER, Judith. Inversões Sexuais. In: PASSOS, Izabel C. Friche (Org.). Poder, normalização e violência. Incursões foucaultianas para a atualidade. Belo Horizonte: Autêntica, 2008.

BUTLER, Judith. Problemas de gênero - Feminismo e subversão da identidade. $7^{\text {a }}$ ed. Rio de janeiro: Civilização Brasileira, 2014.

FACCHINI, Regina. "Sopa de letrinhas?" - movimento homossexual e produção de identidades coletivas nos anos 90: um estudo a partir da cidade de São Paulo. São Paulo. 2002. Dissertação (Mestrado em Antropologia) Departamento de Antropologia do IFCH, UNICAMP, Campinas, SP, 2002a.

FONSECA, Márcio Alves da. Michel Foucault e a constituição do sujeito. São Paulo: Educ, 2003.

FONSECA, Márcio Alves da. Michel Foucault e o direito. São Paulo: Max Liminad, 2002.

FOUCAULT, Michel. História da sexualidade I: a vontade de saber. Tradução Maria Thereza da Costa Albuquerque e J. A. Guilhon Albuquerque. Rio de Janeiro/São Paulo: Paz \& Terra, 2014a.

FOUCAULT, Michel. Microfísica do poder. 29ª reimpressão. São Paulo: Graal, 2011.

FOUCAULT, Michel. Problematização do Sujeito: Psicologia, Psiquiatria e Psicanálise. In: FOUCAULT, Michel. Ditos e Escritos I. $3^{\circ}$ ed. Rio de Janeiro: Forense Universitária, 2014b.

RIO GRANDE DO SUL. Decreto 48.118/2011. Dispõe sobre o tratamento nominal, inclusão e uso do nome social de travestis e transexuais nos registros estaduais relativos a serviços públicos prestados no âmbito do Poder Executivo Estadual e dá providências. Disponível em: https://www.legisweb.com.br/legislacao/?id=156225. Acesso em: 15 jul. 2015.

SALIH, Sara. Judith Butler e a Teoria Queer. São Paulo: Autêntica, 2013. 
Artigo: Poder, verdade e sexo: a padronização de formas de vida pela criação de categorias sexuais, à luz da teoria de Michel Foucault

SÃO PAULO. Lei 10.948/2001. Dispõe sobre as penalidades a serem aplicadas à prática de discriminação em razão de orientação sexual. Disponível em:

http://www.al.sp.gov.br/repositorio/legislacao/lei/2001/lei-10948-05.11.2001.html. Acesso em: 15 jul. $2015 \mathrm{a}$.

SÃO PAULO. SP conta com Ambulatório para Saúde Integral de Travestis e

Transexuais. 2015. Disponível em:

http://www.saopaulo.sp.gov.br/spnoticias/lenoticia2.php?id=241063. Acesso em: 15 jul. $2015 b$. 